\title{
Hot Spots Regulation and Environmental Justice
}

\author{
Rama Mohana R. Turaga ${ }^{a}$, Douglas Noonan', Ann Bostrom \\ ${ }^{\text {a }}$ Indian Institute of Management, Ahmedabad, India \\ ${ }^{\mathrm{b}}$ School of Public Policy, Georgia Institute of Technology, Atlanta, GA \\ ${ }^{c}$ Daniel J. Evan School of Public Affairs, University of Washington, Seattle, WA
}

Accepted manuscript; final version published as:

Turaga, R. M. R., Noonan, D., \& Bostrom, A. (2011). Hot spots regulation and environmental justice. Ecological Economics, 70(7), 1395-1405. doi:10.1016/j.ecolecon.2011.02.016

Corresponding Author: Rama Mohana R Turaga

Public Systems Group, Indian Institute of Management Campus, Vastrapur, Ahmedabad Gujarat 380015, India

Tel: +91-79-66324956

mohant@iimahd.ernet.in 


\begin{abstract}
This paper analyzes whether regulating "hot spots” of toxic air pollution by increasing the spatial resolution of regulation could address environmental justice (EJ) concerns. To examine this question, this paper develops a decision model of a regulator choosing emission controls within a net cost minimizing framework. An empirical application of the model using air toxic emission data for Escambia and Santa Rosa Counties in Florida estimates the emission standards and spatial distribution of risks at a coarse and a finer spatial resolutions. Implications for EJ are analyzed by combining the simulated spatial risk distributions at the two resolutions with the demographic data. Results indicate that different measures of EJ point to different conclusions regarding the question of whether finer resolution regulation alleviates EJ concerns. The paper concludes with a discussion of the implications for EJ policy.
\end{abstract}

Keywords: environmental justice, air toxics, spatial resolution 


\subsection{Introduction}

Environmental justice (EJ) has been one of the central themes of environmental policy debate in the United States over the past decade. The evidence of disproportionate distribution of environmental risks and grassroots political activism in a number of communities across the country led to several policy initiatives to address EJ, including an executive order in 1992 (Brulle and Pellow, 2006). In this paper, we present an ex ante analysis of a specific policy approach primarily aimed at addressing the EJ concerns arising from emissions of air toxics. ${ }^{1}$

The policy approach studied here involves regulation at the local or community scale by characterizing air toxics risks at fine spatial resolutions. Our primary research question is: does spatially finely resolved regulation of toxic air pollutants lead to a more equitable distribution of risks? To address this question, we first develop a decision model of a net cost minimizing regulator and analyze the implications of finer resolution regulation to emission standards. We then apply the model to air toxics data in two counties to simulate how emission standards, spatial distribution of risks, and measures of EJ could change as regulation changes from a coarse spatial resolution to a finer resolution. We show that the evidence of policy effectiveness in addressing EJ concerns depends on the measure of EJ employed. Our analysis also suggests that EJ policies, in order to be effective, require a clear articulation of the goals of EJ and explicit incorporation of those goals into the decision making process of agencies. This study contributes to the growing literature on the analysis of EJ policy effectiveness.

\footnotetext{
${ }^{1}$ Air toxics are one class of air pollutants regulated under the Clean Air Act. These include pollutants such as benzene, formaldehyde, and heavy metals.
} 
This paper is organized as follows. The next sub-section reviews previous research on the evaluation of EJ policies. Section 2 presents some background on the policy approach our paper analyzes. In Section 3, we formulate our research question and describe the methodology used to test our research question. Sections 4, 5, and 6, respectively, present our decision model, empirical analyses, and results. The paper concludes in Section 7 with a brief discussion of the implications of our study for EJ policy.

\subsection{Previous Research}

Some of the early studies on the analysis of EJ policy have focused on evaluating the impact of the EJ executive order (EJEO) 12898 on agency rule making. Bass (1998) utilized two case studies of EJ assessments under the National Environmental Policy Act (NEPA) to recommend "questions" that the federal agencies should address in assessing the EJ implication of NEPA implementation. The U.S. Government Accounting Office, in its recent reports, analyzed three air quality rules promulgated by the U.S. Environmental Protection Agency (EPA) and found that EPA is lacking in clear guidance and tools to effectively incorporate EJEO in its rulemaking (GAO, July, 2005). A more recent study analyzed the Superfund site listing before and after the EJEO and concluded that the implementation of EJEO did not address the inequity in the listing of Superfund sites (O’Neil, 2007). For example, for Superfund sites discovered after the EJEO, ceteris paribus, the probability of listing in a minority or poor community is lower, compared to the sites discovered before the EJEO.

The other prominent federal program aimed at addressing EJ has been the EJ Small Grants (EJSG) Program, the objective of which is to encourage collaborative local solutions to environmental problems in EJ communities. This program funds specific non-profit 
organizations, city, township or county governments, and Native American tribal governments involved in working with EJ communities. ${ }^{2}$ A spatial analysis of this program showed that funds under this program might not be reaching the intended communities and in several counties that received these grants, TRI emissions have actually increased (Vajjhala, 2007). Although TRI emissions represent an imperfect measure of the environmental outcomes intended under the program, this analysis suggests a lack of clarity in the criteria set for funding under the program. In addition to federal policies, several states adopt and implement EJ policies, either on their own or by federal mandates (see Ringquist and Clark, 1999 for a review of state EJ policies). A comprehensive study of state EJ policy adoption tested whether EJ policy at state level represents a protective regulatory policy or a redistributive policy and found that state EJ policies share the characteristics of both policies (Ringquist and Clark, 2002). One of the several findings of this study is that "environmental justice exists in the policy making arena as a shadow rather than as an issue of substance and immediacy” (p: 380). The authors attribute this to the lack of consensus on part of the EJ activist community on such basic issues as the nature of EJ problem and potential solutions to the problem.

Finally, an important component of EJ policy is providing opportunities and avenues for the involvement of EJ communities in the decision making process. A growing trend in this area is the community-based participatory research, which emphasizes "involving community members in identifying issues in need of investigation, collaborating in the conduct of the research, and translating research-based findings into action, including advocacy for policy level change” (Petersen et al., 2006, p: 339). Case study evaluation of some of these efforts,

\footnotetext{
${ }^{2}$ EPA Factsheet available at http://www.epa.gov/compliance/resources/publications/ej/factsheets/fact-sheet-ejsmall-grants-4-08.pdf
} 
especially in California, suggests significant success in the ability of these community-academic partnerships to affect policy change that benefits public health (Petersen et al., 2006; Minkler et al., 2008). The drawback of these case study evaluations is the difficulty in separating the effect of the partnerships from other contextual factors that contribute to the policy change.

Overall, our review suggests that much of the emphasis in the literature has been on the “process” aspects of the EJ policy implementation (e.g., whether the EJ intervention led to a policy change and whether the adopted EJ policies are protective or redistributive in nature). Few studies analyze particular EJ policies from the perspective of the environmental outcomes to the targeted EJ groups. Further, it appears that the effectiveness of EJ policies is impeded by a lack of clarity and agreement on fundamental issues, including the nature of the EJ problem and metrics to assess “justice” or “equity” or “disproportionate impact” (Noonan, 2008). This paper addresses these issues and contributes to the EJ policy literature by analyzing, ex ante, the EJ implications of a specific policy: regulation of air toxics hot spots at fine spatial resolutions.

\subsection{Policy Background}

The increasing use of emissions trading programs in U.S. air pollution policy has brought air pollution "hot spots" ${ }^{3}$ - locations with unacceptably high pollutant concentrations - into focus in recent policy debates. The critics of the trading programs raise the concern that such a policy would result in hot spots near those sources for which it is cheaper to buy permits than abate emissions (e.g., Heinzerling and Steinzor, 2004). Concern about hot spots has been a

\footnotetext{
${ }^{3}$ The National Academies study on future air quality management in the United States defined hot spots as "locales where pollutant concentrations are substantially higher than concentrations indicated by ambient outdoor monitors located in adjacent or surrounding areas (NRC, 2004, p:274).”
} 
driving force of opposition, for example, to EPA's mercury rule (Graham, 2007) and California’s greenhouse emissions regulation (Hanemann, 2008). In addition to concerns related to trading programs, there is also growing evidence of hot spots near roadways due to vehicular air pollution. Zhu et al., (2002), for example, show that the concentration of ultrafine particles within $100 \mathrm{~m}$ of a roadway could be 25 times higher than concentrations beyond $300 \mathrm{~m}$. Addressing hot spots is one of the main challenges facing air quality management in the United States (NRC, 2004).

\subsection{Hot Spots and Air Toxics}

Hot spots with regards to air toxics have been a particular concern for at least three reasons. First, air toxics emissions from a large number of small sources such as dry cleaners and gas stations have the potential to create high localized concentration of emissions in densely populated areas (EPA, 2006a). Second, the sparse ambient monitoring network ${ }^{4}$ for air toxics is unlikely to capture local variations in pollutant concentrations, especially the concentrations close to the emitting sources. Finally, evidence suggests that some population groups (lowincome and minority) may be disproportionately subjected to higher risks from air toxics (e.g., see Morello-Frosch et al., 2001; Dolinoy and Miranda, 2004; Apelberg et al., 2005).

\subsection{Hot Spots Regulation at Fine Spatial Resolutions}

Reduction of risks from hot spots has been an important component of EPA's overall air toxics strategy. The National Air Toxics Program or “Urban Air Toxics Strategy” (EPA, 2000) intended to “characterize exposure and risk distributions....” in “geographic ’hot spots’...” (p: 38712) to achieve the goal of addressing disproportionate impacts of air toxics. Similarly, risk

\footnotetext{
${ }^{4}$ The current national monitoring network for air toxics, called the National Air Toxics Trends Station network, has only 22 monitors across the country and monitors 18 toxic air pollutants (E.P.A, 2004), mainly in large urban areas.
} 
reduction in hot spots is a "near-source" and "community/neighborhood" goal of EPA's Workplan for the National Air Toxics Program and Integrated Air Toxics State/Local/Tribal Program Structure (EPA, 2001).

One approach to deal with hot spots has been to encourage local/community-scale regulation of air toxics at fine spatial resolutions. The rationale behind this approach is that monitoring networks and modeling studies at the national scale (e.g., the National Air Toxics Assessment, which estimates risks at census tract resolution) do not provide adequate spatial resolution to regulate locations of high air toxics concentrations (i.e., hot spots) (e.g., see Dolinoy and Miranda, 2004). Thus, in its latest national air toxics monitoring strategy, instead of expanding the sparse national air toxics monitoring network, EPA decided to use $60 \%$ of its monitoring budget to fund community-scale air toxics efforts (EPA, 2004a). These projects typically involve extensive ambient monitoring or modeling studies to characterize air toxics risks at very fine spatial resolutions. Currently, EPA is supporting projects in about 30 communities across the country, under its community-based air toxics projects program. ${ }^{5}$

Consistent with this approach, EPA has also been developing tools and guidance to model air toxics risks at finely resolved spatial units. An example of this is the recently developed integrated risk assessment tool, the Regional Air Impact Modeling Initiative (RAIMI) (EPA, 2006b). RAIMI is a GIS-based tool that can be used to estimate cancer and non-cancer risks from multiple air toxics emitted from multiple sources at a community resolution. EPA has also published a detailed guidance document for conducting community-scale risk assessments as part of its Air Toxics Risk Assessment Reference Library series (EPA, 2006a).

\footnotetext{
${ }^{5}$ http://www.epa.gov/air/toxicair/community/basic.html. Last accessed on July 8, 2009.
} 
An example of this policy approach is the Strategic Toxic Air Reduction (STAR) program of The Louisville Metro Air Pollution Control District Board. ${ }^{6}$ Based on extensive local monitoring and modeling studies, this program identified 37 stationary source air toxics that pose or may pose risks above a specified health risk goal; nearly 170 facilities are subject to regulation under this program. These facilities must conduct risk assessments to estimate cancer and non-cancer risks posed by their emissions and submit an emission reduction plan to reduce the risks below the health risk goal (Williams, 2007). The U.S. EPA provided financial and technical assistance to design the STAR program.

\subsection{Research Question and Methodology}

As the discussion above illustrates, regulation at finely resolved spatial units is emerging as one of the key approaches to addressing air toxics hot spots. To elucidate the implications thereof, this paper asks: what effects will regulating air toxics at finely resolved spatial units have on the spatial distribution of risks and on environmental justice?

The initial steps of our analysis strategy involve simulating spatial distribution of air toxics risks under regulation at different spatial resolutions. We then assess if and how measures of EJ change as the spatial resolution of regulation increases. The following outlines the methodology we adopt to address our research question:

- We first develop a model of an optimizing decision maker within the context of air toxics regulation, based on previous research and the decision processes described by EPA and state environmental agencies.

\footnotetext{
${ }^{6}$ http://www.louisvilleky.gov/APCD/STAR/. Last accessed on October 16, 2009.
} 
- We then apply this decision model to analyze stationary sources emitting air toxics in Escambia and Santa Rosa counties in Florida. The empirical analysis includes, estimation of: (i) the emission standards a regulator would set and (ii) the resulting spatial distribution of risks under two spatial resolutions of regulation: the census tract and a finer census block resolution. This simulates the risk distribution that would result from a policy aimed at addressing hot spots (i.e., regulation at finer resolution).

- Lastly, we overlay the spatial distributions of risk estimated at each resolution (in the previous step) on to the demographic data in our study area to analyze the EJ implications of spatially finely resolved regulation. We use three different measures of EJ, explained in the later sections.

\subsection{A Model of Air Toxics Decision Making}

The predominant policy tool employed in the management of air toxics in the U.S. is emission standards, which either limit the emissions to a specified level or specify the technology that the regulated entities should employ to control emissions. In order to develop our decision making model, we review the relevant federal and state level regulations.

A key element of consideration in the risk-based regulation of air toxics is the concept of maximum individual risk (MIR). MIR is the lifetime upper-bound risk to which the maximally exposed individual would be exposed. In 1987, in its judgment in the Vinyl Chloride case, the U.S. Court of Appeals for the District of Columbia directed EPA to consider costs of air toxics regulation only after ensuring an acceptable MIR. Since then, MIR has been a constraint that EPA has to meet in its decisions on setting emission standards for air toxics. ${ }^{7}$

\footnotetext{
${ }^{7}$ van Houtven and Cropper (1996) analyzed EPA's air toxics decisions under the Clean Air Act of 1970 and found that EPA considered both the costs and benefits of regulation until the verdict on the Vinyl Chloride case; after the
} 
In its current residual risk regulations, ${ }^{8}$ EPA adopts a two-step decision process, which is consistent with the direction of the court in the Vinyl Chloride case. The first step involves determining the acceptable MIR. The second step sets emission standards, taking into account other factors including the costs of compliance, technological feasibility, and population risks, but only after ensuring that the MIR will not exceed the acceptable level determined in the first step (EPA, 1999b).

A related regulation at the state level is the Air Toxics “Hot spots” Information and Assessment Act enacted by the California Air Resources Board in 1987. This act requires that the facilities that cause "significant” health risks conduct health risk assessments and inform the affected public of those risks. "Significant” health risks are those risks that exceed the threshold risk levels set by the concerned Air Pollution Control Districts (APCD). This threshold risk is similar to MIR under the federal residual risk regulation. Facilities that exceed the threshold risk must submit a "risk audit and reduction plan” for APCD’s approval, in order to bring the risks down to the threshold value.

Consistent with these decision processes and following the previous models of agency decision making in the literature, ${ }^{9}$ the regulator in our decision model chooses emission standards to minimize net costs, subject to the constraint that the MIR does not exceed a threshold level. The MIR, however, is determined as the maximum risk estimated based on a fixed number of locations in space (for example, ambient air monitoring network or the receptor network of an air quality model). Hence, we model the MIR constraint as follows: no spatial location over which risks are regulated should have a risk exceeding the threshold value.

Vinyl Chloride decision, however, EPA did not consider costs in regulating air toxics, unless the estimated MIR was below 1 in 10,000.

${ }^{8}$ Under the residual risk rules, EPA is required to assess the risks that remain after the implementation of technology standards and set additional standards, if required.

${ }^{9}$ Such previous studies include analysis of pesticide regulations (Cropper et al., 1992), Superfund clean-up decisions (Gupta et al., 1992), and state adoptions of strict liability programs (Alberini and Austin, 1999). 


\subsection{Decision Problem Set-up}

Suppose there are $I$ sources $(i=1,2, \ldots, I)$, each emitting $J$ toxic air pollutants

$(j=1,2,3, \ldots ., J)$. First, we assume that the regulator cares about only two types of costs: private costs of compliance for the polluting sources and the health costs of residual risk. We further assume for simplicity that our regulator weighs these two costs equally. For any source $i$ reducing its emissions of pollutant $j$ from the initial level of $Q^{b}{ }_{i j}$ to $Q_{i j}$, and given $M C_{i j}$ (assumed to be strictly convex and increasing) as the marginal cost function for that pollutant and source, the private abatement cost (or compliance costs) takes the form:

$$
\begin{gathered}
C_{p}=\sum_{i=1}^{I} \sum_{j=1}^{J} \int_{Q_{i j}^{b}}^{Q_{i j}} M C_{i j}\left(Q_{i j}\right) d Q_{i j} \\
\partial C_{p} / \partial Q_{i j}<0
\end{gathered}
$$

The second type of costs our regulator is concerned about is the population health costs. We assume here that our regulator quantifies only the health costs associated with cancer risks and that the cancer risks are additive across different toxic pollutants. To develop an expression for these health costs, we begin with the individual cancer risk, ${ }^{10} r_{m}$, defined as:

$$
r_{m}=\sum_{i=1}^{I} \sum_{j=1}^{J} Q_{i j} \beta_{i j m} u_{j} \quad \text { for all individuals } m=1,2,3, \ldots, M
$$

Where,

$Q_{i j} \quad$ Emission rate (gram/second) of pollutant $j$ from $i$ th source

\footnotetext{
${ }^{10}$ Cancer risk is expressed as probability. For example, if the cancer risk is $n$ in a million, then it is expected that there will be ' $n$ ' additional cases of cancer when a million people are exposed to that level of risk.
} 
$\beta_{i j m}$ Exposure concentration, in $\left[\left(\mu g / m^{3}\right) /(g / s)\right]$, an individual $m$ is exposed to due to a unit emission rate $(1 \mathrm{~g} / \mathrm{s})$ of pollutant $j$ from source $i=f$ (meteorology, emission and site characteristics, location of $m$ with respect to the source, activity patterns of individuals, etc.,)

$u_{j} \quad$ Unit Risk Factor for $j$ th pollutant, $\left(\mu g / \mathrm{m}^{3}\right)^{-1}$, which represents the probability of cancer due to continuous exposure for 70 years to $1 \mu \mathrm{g} / \mathrm{m}^{3}$ of pollutant $j$

For $M$ individuals (indexed $m=1,2, \ldots, M$ ) exposed, the total population risk (i.e., the total number of expected additional cancer cases) is merely the sum of all the individual risks. Assuming that the value of statistical life (VSL) is constant across all individuals, the population health costs could be estimated simply as the product of the total number of expected additional cancer cases and the VSL $(V) .{ }^{11}$ Thus, the health costs associated with cancer are given as:

$$
\begin{gathered}
C_{h}=\sum_{m=1}^{M} r_{m} V \\
\partial C_{h} / \partial Q_{i j}>0
\end{gathered}
$$

The MIR constraint requires that the maximum cancer risk not exceed the threshold value of $r$. Let $K$ be spatial resolution at which risks are regulated. Here $K$ represents the number of locations, within a geographic area of interest, over which risks are regulated. The MIR constraint for regulating risks at spatial resolution $K$ can be expressed as:

$$
\sum_{i=1}^{I} \sum_{j=1}^{J} Q_{i j} \beta_{i j k} u_{j} \leq r \quad \forall k=1,2,3, \ldots, K
$$

\footnotetext{
${ }^{11}$ This assumes that incidence of cancer results in mortality and that VSL is constant across additional cancer cases. Because $V$ enters as a scalar, it implies that there is no heterogeneity across individuals in their willingness to pay to reduce the risk of death.
} 
where $\beta_{i j k}$ is the exposure concentration due to unit emissions at any given spatial location $k$.

$K$ is a variable of interest for the research question addressed here. A finer spatial resolution of regulation would then mean an increase in the number of receptor locations over which risks are regulated. In other words, $K$ is increasing with spatial resolution. ${ }^{12}$ Regulating over census tracts instead of counties, for example, implies increasing $K$.

The decision maker's objective function is thus:

$\operatorname{Min}_{Q_{i j}}\left\{\left(\sum_{i=1}^{I} \sum_{j=1}^{J} \int_{Q_{i j}^{b}}^{Q_{i j}} M C_{i j}\left(Q_{i j}\right) d Q_{i j}\right)+\left(\sum_{i=1}^{I} \sum_{j=1}^{J} \sum_{m=1}^{M} Q_{i j} \beta_{i j m} u_{j} V\right)\right\}$

subject to the constraints in equation (6) and the non-negative emissions constraints:

$$
Q_{i j} \geq 0
$$

In the next section, we apply this decision model ${ }^{13}$ to air toxics data of two counties, Escambia and Santa Rosa in Florida, to first estimate the emission standards a regulator would choose under a coarse resolution $(K)$ and a finer resolution $\left(K^{\prime}>K\right)$. The emission standards under the two resolutions of regulation will then be used to estimate the resulting spatial distribution of risks at each resolution. Finally, we combine these risk estimates with demographic data to analyze the EJ implications of regulating at finer spatial resolutions.

\footnotetext{
${ }^{12}$ Our conception of finer resolution here is simply an increase in the number of spatial locations over which risks are regulated. The implicit assumption is that the location of new receptors at the finer resolution is arbitrarily determined, which appears to be the case in the real world (Su et al., 2007).

${ }^{13}$ The full analytical solution for the model is available from the authors. The basic result is that the optimal emission standards at finer regulation could be stricter, laxer, or unchanged relative to the emission standards at coarse regulation. The direction of change depends on (i) whether or not the finer resolution reveals new hot spots that are not revealed at coarse resolutions and (ii) how much a source/pollutant contributes to the risk at those new hot spots. The full solution is not included here due to space constraints.
} 


\subsection{Empirical Analysis}

Our study area consists of two counties in Northwest Florida: Escambia and Santa Rosa. This region has a history of problems related to toxic pollutants and environmental justice. One of the most publicized problems has been the case of "Mount Dioxin," a Superfund site of Escambia Treating Company. The dioxin contamination from this site prompted grassroots level action and led to relocation of people living near the site (see Bullard and Johnson, 2000). More recent concerns relate to the quantities of toxics emissions. According to the toxic release inventory data of 2005, Escambia county was ranked top and Santa Rosa was ranked $9^{\text {th }}$ in Florida in terms of total tons of toxics released into various media. Responding to public concerns related to environmental impacts, the US Congress sponsored the Partnership for Environmental Research and Community Health (PERCH) to conduct a series of environmental health studies, including an assessment of air toxics risks in the region (UWF, 2011).

According to the National Toxics Inventory (NTI) of 1999, our study area had 94 air toxics emission sources distributed across 43 facilities, including manufacturing plants, utilities, and waste landfills, and emitting 78 different air toxics. The sources include "major" ${ }^{14}$ sources as well as "area"15 sources. Many of these sources are currently regulated under the Maximum Achievable Control Technology (MACT) standards developed by the federal EPA under the CAA. Florida, to the best of our knowledge, does not have a separate state program that regulates the sources of air toxics. Florida department of environmental protection, however,

\footnotetext{
${ }^{14}$ A "major" source is one that emits more than 10 tons per year (TPY) of any one of the regulated air toxics or more than 25 TPY of a combination of air toxics.

15 “Area” sources emit quantities below the thresholds specified for "major" sources.
} 
issues operating permits in accordance with the federal regulations and enforces compliance with the permits.

We use two criteria to select a subset of the 94 sources for our analysis: (1) the source is categorized as a "major" source and (2) the source emits at least one toxic air pollutant for which inhalation cancer risk can be quantified (because our model assumes quantification of only cancer risks). Based on these criteria, our final sample includes 15 sources from seven facilities, which emit six different air toxics. ${ }^{16}$

The empirical analysis uses three nested spatial resolutions: census tract, census block group, and census block. ${ }^{17}$ The census tract ("tract” from hereon) is the biggest spatial unit and is composed of several census block groups (“block group” from hereon) while the census block (“block” from hereon) is the finest spatial unit with a number of blocks forming a block group.

Furthermore, in the empirical analysis, because it is not possible to estimate risks at the individual level, we apply the risk estimated at the geographical centroid of a census unit to all the individuals within that census unit. Finally, consistent with the theoretical decision model, in our empirical analysis, finer resolution is assumed to include all those locations over which risks would be regulated at the coarse resolution in addition to the new receptors. Thus, for example, the receptors for regulation at the block group resolution include not only the centroids of all the block groups but also that of all the census tracts. General Algebraic Modeling System (www.gams.com) version 22.3 is used to solve the optimization model.

\subsection{Data}

\footnotetext{
${ }^{16}$ We dropped one facility that met our criteria from the final sample because no abatement cost information was available.

${ }^{17}$ The choice of census unit to characterize spatial resolution is one of convenience; with the advent of advanced remote sensing technologies to characterize air pollution, it is perhaps possible to regulate at much finer resolutions than those we choose here.
} 


\subsubsection{Marginal Cost (MC) Functions}

We estimate marginal MC functions using an engineering cost approach, which is a common method in the literature (e.g., Kilmont et al., 2000; EPA, 2003; Karvosenoja and Johansson, 2003; Rousseau and Proost, 2005). Ideally, the MC functions should be derived for each source based on the data specific to the source. In reality, however, such information is rarely available, if ever, especially for air toxics. Thus in our case, we make some assumptions to make sense of the little that data are available. Specifically, we assume that each of the sources in our analysis represents a "typical” or “average” firm in that source category. We rely on EPA's abatement costs estimates under its technology-based MACT standards. EPA is required to conduct Regulatory Impact Analyses (RIA) to assess the costs and benefits of its costly regulations. In case of MACT standards, the EPA assessed the costs of a range of available abatement technologies for each regulated source category. To estimate the cost functions for our empirical analysis, we first identify the MACT standards relevant to the air toxics sources in our sample. We then use the air permit documents available from the Florida Department of Environmental Protection to match our sources with the corresponding MACT standard.

After identifying the relevant MACT for each source, we collect, from the relevant RIAs, the information on the emission control options including the range of control technology options available, the emission reductions associated with each technology option, and the annual costs of implementing the technology. ${ }^{18}$ The annual costs include estimated annualized capital costs as well as operational costs. Because these studies were carried out in different

\footnotetext{
${ }^{18}$ This data on abatement technology options, removal efficiencies, and annual costs for each source are available from the authors on request.
} 
years, we convert all costs into 1999\$. Typically, the RIAs report total compliance cost estimates aggregated at the level of the source category. The estimates, however, report the number of firms on which these aggregate estimates are based. Thus, for an "average” firm, the estimated costs could be calculated as the total sector-wise annual costs divided by the number of firms. Based on our assumption that the source in our analysis represents an "average” source in that category, we use the cost estimates generated in the previous step for our empirical analysis In this analysis, in order to be consistent with the assumptions of our decision model (i.e., strictly convex and increasing MC functions), we fit our cost estimates to an exponential functional form. Another advantage of an exponential form for our analysis is that this functional form restricts the estimated annual costs to positive values. This is also consistent with previous studies, which assumed either a quadratic form (Hartman et al., 1997) or an exponential function (Mariam and Barre, 1996).

$$
C_{i j}=a_{i j} e^{b_{i j} Q_{i j}}
$$

$C_{i j}=$ Annual costs of abatement for pollutant $j$ from source $i$ (\$)

$Q_{i j}=$ Emission levels of pollutant $j$ from source $i$ (Ton/Year)

$a_{i j}, b_{i j}=$ Parameters to be estimated

The cost function is fitted using non-linear least squares regressions with the annual costs as the dependent variable and emission level (TPY) as the independent variable. The estimated cost parameters for various sources are given in Table 1 . The table also shows the standard errors for the coefficient estimates. Because the data for some sources had only two abatement technology options, the standard errors could not be estimated. 
[TABLE 1 APPROXIMATELY HERE]

\subsubsection{Exposure Concentrations ( $\beta_{i j m}$ )}

Application of the decision model to simulate the optimal emission standards a regulator would set requires estimation of exposure concentrations at the centroids of various census units. This analysis estimates the annual average ambient air toxics concentrations using the version 3 of the Industrial Source Complex Short Term (ISCST3) ${ }^{19}$ air dispersion model, integrated within RAIMI, the integrated risk assessment tool developed by EPA. RAIMI uses a geographical information system (GIS) interface. The GIS data required for RAIMI include (i) land use and land cover maps, which we obtained from Florida Geographic Data Library, (ii) digital elevation maps, which we collected from the United States Geological Survey, and (iii) aerial photographs of the two county region, downloaded from Terra Server (http://terraserver.microsoft.com).

The ISCST model also requires hourly upper air and surface meteorological data. We use EPA’s Meteorological Preprocessor for Regulatory Models to process the raw meteorological data collected at the Pensacola Airport for the years 1986 to 1990. Although the theoretical model requires that we estimate the exposure concentrations, we use the ambient air toxics concentrations as surrogates for exposure concentrations because RAIMI does not incorporate an exposure model. In addition, the risk estimation within RAIMI is based on the assumption that individuals would be exposed to the same estimated exposure concentrations throughout their lifetime. This is not realistic but it is very difficult, if not impossible, to predict

\footnotetext{
${ }^{19}$ ISCST3 is a steady-state, multiple source, Gaussian dispersion model and has been the preferred regulatory model for industrial sources until it was replaced by AMS/EPA Regulatory Model (AERMOD) in 2005 (FR, 2005)
} 
the lifetime exposures, which depend on the environment in which the individual will live in his/her entire lifetime.

\subsubsection{Other Data}

With regards to the other data, we adopt a value of \$5.5 million (1999\$) for VSL (V in the model). This is the same value EPA used for its benefit cost assessment of the Clean Air Act (EPA, 1999a) for 1990-2010 (EPA used a mean VSL of \$4.8 million in 1990\$, which is \$5.5 million in 1999\$). The baseline emissions $\left(\boldsymbol{Q}^{\boldsymbol{b}}{ }_{\boldsymbol{i}}\right.$ in the decision model) represent current emissions according to the 1999 NTI for the sources and pollutants selected for the empirical analysis. Values of unit risk factors, $u_{j}$, for each of the six pollutants in the sample are obtained from EPA's Integrated Risk Information System database. The values used in the analysis are: 0.0000078 for benzene, 0.0000022 for acetaldehyde, 0.000013 for formaldehyde, 0.000068 for acrylonitrile, 0.00024 for nickel, and 0.0043 for arsenic. Finally, we obtain the population data from the US Census Bureau for the year 2000. 


\subsection{Results}

\subsection{Emission Standards}

Table 2 shows the estimated emission standards at three spatial resolutions under a MIR constraint of 100 in a million. The emission standards do not change at the block group resolution compared to a coarser census tract resolution. This is because regulation at block group resolution for our empirical setting does not capture any new hot spots. The last column of Table 2 shows the emission standards at the finest (block) resolution. Compared to regulation at coarser resolution, the emissions at this resolution are higher for a majority of sources and lower for some sources - resolution of regulation at the block level captured new hot spots that would not have been regulated at the coarser resolutions. Table 3 shows the estimated emission standards under different resolutions of regulation at a more restrictive threshold cancer risk of 10 in a million.

\section{[TABLE2 2 and 3 APPROXIMATELY HERE]}

\subsection{Spatial Distribution of Cancer Risk}

We use these emission standards, $Q_{i j}^{*}$, to estimate cumulative excess individual cancer risk, $r_{b}$, attributable to air toxics exposures at the centroid of each census block $(b=1,2, \ldots, B)$ in our two-county region for each spatial resolution of regulation. By estimating risk at the centroid, we assume that each individual in the census block is exposed to that risk level. We calculate the cancer risk with the following equation (the terms are defined as before): 


$$
r_{b}=\sum_{i=1}^{I} \sum_{j=1}^{J} Q_{i j}^{*} \beta_{i j b} u_{j} \quad \forall b=1,2,3, \ldots ., B
$$

Figures 1 shows the spatial distribution of cancer risks when air toxics are regulated at the tract resolution with the threshold risk constraint of 100 in a million. Figure 2 shows the spatial distribution at the block resolution regulation for the same threshold risk. Figures 3 and 4 show the spatial distribution of cancer risk for tract and block regulation, respectively, at the 10 in a million risk threshold.

[FIGURES 1 to 4 APPROXIMATELY HERE]

\subsection{Environmental Justice Analysis}

The first EJ measure we use is based on an interpretation of EJ by the EPA: "Environmental Justice is the fair treatment and meaningful involvement of all people regardless of race, color, national origin, or income with respect to the development, implementation, and enforcement of environmental laws, regulations, and policies. Fair treatment means that no group of people should bear a disproportionate share of the negative environmental consequences resulting from industrial, governmental and commercial operations or policies.” (EPA, 2008)

Based on this interpretation, we assess the EJ implication of regulation at finer resolution by using the following measure:

\section{EJ Measure 1: No population group should be disproportionately exposed to hot spots.}


In this measure, the "negative environmental consequence" is the probability of an adverse health outcome, which in our case is the risk of cancer. If one defines hot spots as the locations at which the risk of an adverse health outcome is above an acceptable threshold, as we have defined in this paper, then a comparison of Figure 1 and Figure 2 shows that the regulation at finer block resolution would eliminate the hot spots that would have resulted from a coarse regulation (the blocks in black in Figure 1 are no longer seen in Figure 2). This holds true at the 10 in a million threshold risk (Figures 3 and 4) as well. The result is not surprising because at the block regulation, our decision model constrains the risk in each block to the acceptable threshold risk. Thus, by this definition of EJ, under the regulation at finer spatial resolution, no group is disproportionately exposed to unacceptable risk levels.

The second measure we use is based on the "disproportionately adverse effect” definition developed by EPA in its EJ toolkit for staff.

“....the term disproportionately high and adverse effects or impacts means an adverse effect or impact that: (1) is predominately borne by any segment of the population, including a minority population and/or a low-income population; or (2) will be suffered by a minority population and/or low-income population and is appreciably more severe or greater in magnitude than the adverse effect or impact that will be suffered by a nonminority population and/or non-low-income population.” (EPA, 2004b, p: 71)

The toolkit also emphasizes that, to assess whether an EJ concern exists, the adverse impacts in the communities of concern should be compared to the impacts in reference communities. In our interpretation of this guidance, a "community of concern" is any census block in which the proportion of minority population is higher than the proportion of minority 
population in our study area as a whole. The proportion of minorities in our study area is $22.4 \%$ and thus any block group that has a minority population share of more than $22.4 \%$ is a community of concern for our analysis. To assess the EJ implications, we compare the mean individual cancer risk in communities of concern to the mean individual risk in all other communities. Base on this classification, our EJ measure is:

\section{EJ Measure 2: On average, communities with a larger proportion of minorities than the region as a whole should not be exposed to greater individual cancer risks than the other communities.}

Table 4 shows the results of our analysis. At the tract resolution, the mean individual risk in the communities of concern is significantly higher than the mean risk in the reference communities. This is the case for both the 100 in a million and 10 in a million risk thresholds. If the regulation at finer resolution were to address the EJ concern, as defined by our measure, the difference in mean risk between the two communities should be statistically insignificant at the finer block resolution. However, as the table 4 shows, that is not the case. The mean individual cancer risk at the finer block resolution is statistically higher in the communities of concern at both the threshold risks. Thus, the regulation at finer resolutions does not address the EJ concerns, as defined by this second measure.

Our third EJ measure is based on a population risk measure. The previous two measures are based on individual risk, which represents the probability that an individual will develop a cancer when exposed to a certain concentration of air toxics. The population risk is simply the 
sum of individual risks in a population. For example, if a million people are exposed to a 1 in a million risk, the expected population risk is one case of cancer. ${ }^{20}$

At any given resolution of regulation, we assess equity with respect to the population risk using the following measure:

$$
E J P O P_{i}=\frac{C C_{i} / \sum_{i} C C_{i}}{P O P_{i} / \sum_{i} P O P_{i}} \quad i=\text { White, Non-white }
$$

Where

$$
C C_{i}=\text { Additional Expected Cancer Cases for Racial Group } i
$$

$$
P O P_{i}=\text { Population of Racial Group } i
$$

In a just world, each population group should have a value of one for this measure. A value greater (less) than one indicates that the group bears a greater (lower) share of the expected cancer cases relative to the share of their population.

[TABLE 4 APPROXIMATELY HERE]

\section{EJ Measure 3: The share of expected additional cancer cases for minorities as a proportion of their share of total population should be equal to one.}

Figure 5 and Figure 6 show the results of the analysis with respect to our population risk EJ measure. Both figures show that at tract resolution as well as block resolution, the EJ

\footnotetext{
${ }^{20}$ One can argue that the population risk is a more appropriate measure because it weights the risk by population. For example, if two census blocks are exposed to same individual risk but if one of the blocks has a much higher population than the other, the individual risk measure will not capture the fact that the overall risk is greater in the block with larger population.
} 
measure is greater than one for nonwhites and less than one for whites. As explained earlier, this result indicates that nonwhites would share a greater share of expected cancer cases relative to their share of population and this situation is not alleviated at a finer resolution regulation. That is, if finer resolution regulation were to address EJ concerns, our EJ measure should reduce from greater than one at tract resolution to one at block resolution, which does not happen either at 100 in a million threshold risk scenario or at the 10 in a million risk threshold scenario. This suggests that the regulation at finer resolutions is unlikely to adequately address EJ concerns as defined by our third measure.

[FIGURES 5 and 6 APPROXIMATELY HERE]

\subsection{Discussion and Implications}

Regulation of air toxics at finely resolved spatial units has been emerging as an approach to deal with hot spots. Given that addressing EJ concerns is one of the primary rationales for regulating hot spots, our goal in this paper was to analyze, ex ante, whether the policy of finer regulation of hot spots could address EJ concerns. Based on the interpretation of various regulations and guidelines on EJ, we constructed three measures of EJ in order to evaluate the policy. Our analysis suggests that increasing the resolution of regulation could change the spatial distribution of risk in such a way that the risk in hot spots (i.e., locations with risk levels beyond some acceptable level) is mitigated; the change in the distribution of risk might not, however, translate to a more equitable distribution of risk across racial groups. In other words, 
the policy of finer resolution regulation would be a protective regulatory policy but not a redistributive policy in a way that it addresses EJ concerns.

It is possible to argue that our results are not necessarily generalizable across all situations and locations. That is, it is conceivable that under some other empirical settings, spatially finer regulation would result in redistribution of risks in a way that addresses the EJ concerns, even within our modeled decision framework. Such an outcome would, however, be a result of chance rather than design. Even assuming that redistribution of risks in a way that equalizes risks across racial groups is the goal of EJ policies (which itself is not clear), the current decision process, as reflected by our model, incorporates only a general equity constraint and has no provision that explicitly addresses EJ goals. This would, by design, ensure only a protective policy.

Thus in order to guide future EJ policy, EPA and the other state agencies, in collaboration with the potentially affected EJ communities, should develop well-defined EJ goals and explicitly incorporate those goals into the decision process. For example, if the goal is redistribution of risks from the EJ groups to the other groups, then such a goal could be incorporated into the decision process by specifying location-specific constraints. One such location-specific constraint could be that locations, in which the percentage of the minorities exceeds the overall percentage of the minorities in the region, should be subjected to stricter risk threshold standard than other locations. Such a constraint is easy to incorporate into the decision framework we modeled here. The challenge, however, is to arrive at a basis for specifying the location-specific risk thresholds. What should be the risk threshold for minority areas relative to other areas in the region? This question gets complicated because of the lack of conclusive 
evidence or guidance on the extent (quantitatively) to which EJ groups are more susceptible than other groups to exposure from air pollution (see Sexton, 1997 and Post et al., 2009 for a discussion).

Another implication of our findings is that the assessment of EJ policy success could depend on the definition of EJ goals. In the context of the policy we analyzed, if the goal is to ensure that the EJ communities are not exposed to adverse environmental impacts greater than some acceptable threshold levels, then the finer regulation policy meets that goal by design. If the goal, however, is to redistribute risk such that the adverse impacts are equalized across groups, then the policy of finer resolution regulation may not help. This suggests that agencies should develop clear metrics for measuring the effectiveness of EJ policies, in addition to specifying well-defined EJ goals.

Future extensions to our paper can take several paths. A potentially interesting path is to investigate the implications of our assumptions, in the decision model as well as empirical analysis, for the main findings. First is the assumption that there is no variation in susceptibility to air toxics exposures across population groups. It is straightforward to incorporate such a variation into our model and empirical analysis if concentration-response functions (cancer unit risk factors in the case of toxic air pollutants) can be specified differently for different population groups. Such subgroup-specific risk factors are currently not available ${ }^{21}$, however (Sexton, 1997; Post et al., 2009). Second, due to limitations in the abatement cost data, we used the cost functions for an "average” firm in a given source category as a proxy for source-specific cost

\footnotetext{
${ }^{21}$ The only exception with regards to cancer risk assessment is the case of children. In its "Supplemental Guidance for Assessing Susceptibility from Early-Life Exposure to Carcinogens” the EPA recommends incorporating age dependent adjustment factors (ADAFs) in the dose-response relationships (EPA, 2005b). For example, EPA recommends an ADAF of 10 for exposures before age 2 and an ADAF of 3 for exposures between the ages 2 and 16.
} 
functions. Although source-specific functions are unlikely to significantly alter our main findings, future research could use the more accurate plant-specific cost functions, if available.

Third, we assumed constant VSL across individuals. Theoretical and empirical evidence in environmental economics indicates that VSL could vary with such factors as age, income, and baseline risk (Hammitt, 2000). The evidence, however, does not appear conclusive (Krupnick, 2007) and thus the current regulatory analysis continues to be based on constant VSL (EPA, 2007). In our case, we expect that a varying VSL will affect the risk distributions at coarse and finer regulation in a similar fashion. Thus a varying VSL is unlikely to change our main findings significantly because our analysis is based on the differences in risk distribution between regulation at the coarse resolution and a finer resolution. Again, it is straightforward to incorporate individual-specific VSL into our model and empirical analysis and we wish to incorporate such variations in future extensions.

\section{Acknowledgments}

Much of this work was carried out during Turaga's tenure first as a graduate student at the Georgia Institute of Technology, Atlanta, GA and then as a Research Associate at Dartmouth College, Hanover, NH. We gratefully acknowledge research support from the University of West Florida (UWF) Sub Award \# 2519-229-22(02). The prime award is from the U.S. EPA (Award \# /x974550002-3) for the Partnership for Environmental Research and Community Health (PERCH) project. We would also like to acknowledge Mark Borsuk and two anonymous reviewers for their valuable inputs to the manuscript. 


\section{References}

Alberini, A., Austin, D., 1999. On and Off the Liability Bandwagon: Explaining State Adoptions of Strict Liability in Hazardous Waste Programs. J. Regul. Econ. 15, 41-64.

Apelberg, B.J., Buckley, T.J., White, R.H., 2005. Socioeconomic and Racial Disparities in Cancer Risk from Air Toxics in Maryland. Environmental Health Perspectives 113, 693.

Bass, R., 1998. Evaluating environmental justice under the national environmental policy act. Environmental Impact Assessment Review 18, 83-92.

Brulle, R.J., Pellow, D.N., 2006. Environmental Justice: Human Health and Environmental Inequalities. Annual Review of Public Health 27, 103-124.

Bullard, R.D., Johnson, G.S., 2000. Environmental justice: Grassroots activism and its impact on public policy decision making. Journal of Social Issues 56, 555-578.

Cropper, M.L., Evans, W.N., Berardi, S.J., Ducla-Soares, M.M., Portney, P.R., 1992. The Determinants of Pesticide Regulation: A Statistical Analysis of EPA Decision Making. J. Polit. Economy 100, 175-197.

Dolinoy, D.C., Miranda, M.L., 2004. GIS Modeling of Air Toxics Releases from TRI-Reporting and Non-TRI-Reporting Facilities: Impacts for Environmental Justice. Environmental Health Perspectives 112, 1717-1724.

E.P.A, 2004. National Monitoring Strategy: Air Toxics Component. U.S. Environmental Protection Agency, Office of Air Quality Planning and Standards. Accessed from on EPA, 1999a. The Benefits and Costs of the Clean Air Act, 1990 to 2010. EPA-410-R-99-001, Office of Air and Radiation, Washington, DC. Accessed from on 
EPA, 1999b. Residual Risk Report to Congress. US Environmental Protection Agency, Office of Air and Radiation, Office of Air Quality Planning and Standards. Accessed from on EPA, 2000. National Air Toxics Program: The Integrated Urban Strategy'. Office of Air Quality Planning and Standards, Research Triangle Park, North Carolina, July, 99-007.

EPA, 2001. Workplan for the National Air Toxics Program and Integrated Air Toxics State/local/tribal Program Structure. Emission Standards Division, Office of Air Quality Planning and Standards. Accessed from on

EPA, 2003. International Analysis of Methane and Nitrous Oxide Abatement Opportunities: Report to Energy Modeling Forum. Accessed from http://www.epa.gov/climatechange/economics/pdfs/methodologych4.pdf on 18 February 2011

EPA, 2004a. National Monitoring Strategy: Air Toxics Component. U.S. Environmental Protection Agency, Office of Air Quality Planning and Standards. Accessed from on EPA, 2004b. Toolkit for Assessing Potential Allegation of Environmental Injustice. Office of Environmental Justice. Accessed from on

EPA, 2006a. Air Toxics Risk Assessment Reference Library Volume 3, Community-Scale Assessment. Accessed from http://www.epa.gov/ttn/fera/risk_atra_vol3.html on EPA, 2006b. RAIMI - Regional Air Impact Modeling Initiative. Accessed from http://www.epa.gov/earth1r6/6pd/rcra_c/raimi/raimi.htm on 12 March 2006 EPA, 2007. SAB Advisory on EPA's issues in valuing mortality risk reduction. Office of the Administrator, Science Advisory Board, October 12, 2007. Accessed from 
http://yosemite.epa.gov/sab\%5Csabproduct.nsf/4128007E7876B8F0852573760058A978/ \$File/sab-08-001.pdf on 16 August 2010

EPA, 2008. Environmental Justice: Basic Information. Accessed from http://www.epa.gov/compliance/basics/ejbackground.html on 31 October, 2008

FR, 2005. Revision to the Guideline on Air Quality Models: Adoption of a Preferred General Purpose (Flat and Complex Terrain) Dispersion Model and Other Revisions, Final Rule. Federal Register, pp. 68217-68261.

GAO, July, 2005. EPA Should Devote More Attention to Environmental Justice When Developing Clean Air Rules. GAO-05-289. Accessed from on

Graham, J.D., 2007. The Evolving Regulatory Role of the U.S. Office of Management and Budget. Review of Environmental Economics and Policy 1, 171-191.

Gupta, S., Van Houtven, G., Cropper, M., 1992. Paying for Permanence: An Economic Analysis of EPA's Cleanup Decisions at Superfund Sites. RAND J. Econ. 27, 563-582.

Hammitt, J.K., 2000. Valuing mortality risk: theory and practice. Environmental Science \& Technology 34, 1396-1400.

Hanemann, M., 2008. California's New Greenhouse Gas Laws. Review of Environmental Economics and Policy 2, 114-129.

Hartman, R.S., Wheeler, D., Singh, M., 1997. The cost of air pollution abatement. Appl. Econ. 29, $759-774$.

Heinzerling, L., Steinzor, R.I., 2004. A Perfect Storm: Mercury and the Bush Administration, Part II. Environmental Law Reporter 34, 10485-10497. 
Karvosenoja, N., Johansson, M., 2003. Cost curve analysis for SO2 and NOx emission control in Finland. Environmental Science \& Policy 6, 329-340.

Kilmont, Z., Amann, M., Cofala, J., 2000. Estimating costs for controlling emissions of volatile organic compounds (VOC) from stationary sources. International Institute for Applied Systems Analysis, Austria. Accessed from http://www.iiasa.ac.at/Admin/PUB/Documents/IR-00-051.pdf on 18 February 2011

Krupnick, A., 2007. Mortality-risk valuation and age: stated preference evidence. Review of Environmental Economics and Policy 1, 261.

Mariam, Y., Barre, M., 1996. VOCs's cost functions in the design of emission abatement strategies. MPRA Paper No. 658. Accessed from on

Minkler, M., Vasquez, V.B., Tajik, M., Petersen, D., 2008. Promoting Environmental Justice Through Community-Based Participatory Research: The Role of Community and Partnership Capacity. Health Education \& Behavior 35, 119.

Morello-Frosch, R., Pastor, M., Sadd, J., 2001. Environmental Justice and Southern California's" Riskscape": The Distribution of Air Toxics Exposures and Health Risks Among Diverse Communities. Urban Affairs Review 36, 551.

Noonan, D.S., 2008. Evidence of Environmental Justice: A Critical Perspective on the Practice of EJ Research and Lessons for Policy Design. Social Science Quarterly 89, 1153-1174.

NRC, 2004. Air quality management in the United States. National Academies Press, Washington, D.C.

O’Neil, S.G., 2007. Superfund: Evaluating the Impact of Executive Order 12898. Environmental Health Perspectives 115, 1087. 
Petersen, D., Minkler, M., Vasquez, V.B., Baden, A.C., 2006. Community-Based Participatory Research as a Tool for Policy Change: A Case Study of the Southern California Environmental Justice Collaborative. Review of Policy Research 23, 339-354.

Post, E., McCubbin, D., Belova, A., Huang, J., Frey, N., 2009. Methodology for Distributional Benefit Analysis of a National Air Quality Rule. Report Prepared for EPA/NCEE by Abt Associates. Accessed from http://yosemite.epa.gov/ee/epa/eerm.nsf/vwAN/EE-052001.pdf/\$file/EE-0520-01.pdf on 10 February 2011

Ringquist, E.J., Clark, D.H., 1999. Local Risks, States' Rights, and Federal Mandates:

Remedying Environmental Inequities in the US Federal System. Publius: The Journal of Federalism 29, 73.

Ringquist, E.J., Clark, D.H., 2002. Issue definition and the politics of state environmental justice policy adoption. International Journal of Public Administration 25, 351-389.

Rousseau, S., Proost, S., 2005. Comparing environmental policy instruments in the presence of imperfect compliance-A case study. Environ. Resource Econ. 32, 337-365.

Sexton, K., 1997. Sociodemographic aspects of human susceptibility to toxic chemicals: Do class and race matter for realistic risk assessment? Environmental Toxicology and Pharmacology 4, 261-269.

Su, J.G., Larson, T., Baribeau, A.M., Brauer, M., Rensing, M., Buzzelli, M., 2007. Spatial Modeling for Air Pollution Monitoring Network Design: Example of Residential Woodsmoke. Journal of the Air \& Waste Management Association 57, 893-900.

UWF, 2011. Partnership for Environmental Research and Community Health (PERCH). Accessed from http://uwf.edu/cedb/perch.cfm on 11 February 2011 
Vajjhala, S., 2007. Building Community Capacity? Mapping the Scope and Impacts of the EPA Environmental Justice Small Grants Program. Resources for the Future. Accessed from on

van Houtven, G., Cropper, M.L., 1996. When is a life too costly to save? The evidence from US environmental regulations. J. Environ. Econ. Manage. 30, 348-368.

Williams, A., 2007. Louisville 2005: STAR Adopted. Accessed from http://www.louisvilleky.gov/APCD/STAR/ on 16 April 2007

Zhu, Y., Hinds, W.C., Kim, S., Sioutas, C., 2002. Concentration and Size Distribution of Ultrafine Particles Near a Major Highway. Journal of the Air \& Waste Management Association 52, 1032-1042. 
Table 1 Details of Cost Function Parameters Used in Empirical Analysis

\begin{tabular}{|c|c|c|c|c|}
\hline \multirow[t]{2}{*}{ Facility } & \multirow[t]{2}{*}{ Source } & \multirow{2}{*}{$\begin{array}{l}\text { Pollutants } \\
\text { Emitted }\end{array}$} & \multicolumn{2}{|c|}{ Cost Parameters } \\
\hline & & & $a_{i j}$ & $b_{i j}$ \\
\hline \multirow[t]{2}{*}{ IP } & Bleaching Line Vent & Acetaldehyde & $\begin{array}{c}5303579 \\
(1230)\end{array}$ & $\begin{array}{c}-0.019 \\
(0.0001)\end{array}$ \\
\hline & Pulping System Vent & $\begin{array}{l}\text { Formaldehyde, } \\
\text { Acetaldehyde, } \\
\text { Benzene }\end{array}$ & $\begin{array}{c}27600000 \\
\left(2.17 \mathrm{e}^{+} 06\right)\end{array}$ & $\begin{array}{l}-0.005 \\
(0.0013)\end{array}$ \\
\hline \multirow[t]{4}{*}{ GP } & Boiler & $\begin{array}{l}\text { Formaldehyde, } \\
\text { Acetaldehyde, } \\
\text { Benzene }\end{array}$ & $\begin{array}{l}755887 \\
(48729)\end{array}$ & $\begin{array}{l}-0.083 \\
(0.013)\end{array}$ \\
\hline & Boiler & $\begin{array}{l}\text { Formaldehyde, } \\
\text { Acetaldehyde, } \\
\text { Benzene }\end{array}$ & $\begin{array}{l}755887 \\
(48729)\end{array}$ & $\begin{array}{l}-0.083 \\
(0.013)\end{array}$ \\
\hline & Boiler & $\begin{array}{l}\text { Formaldehyde, } \\
\text { Acetaldehyde, } \\
\text { Benzene }\end{array}$ & $\begin{array}{l}755887 \\
(48729)\end{array}$ & $\begin{array}{l}-0.083 \\
(0.013)\end{array}$ \\
\hline & Boiler & $\begin{array}{l}\text { Nickel, } \\
\text { Arsenic }\end{array}$ & $\begin{array}{l}755887 \\
(48729)\end{array}$ & $\begin{array}{l}-0.083 \\
(0.013)\end{array}$ \\
\hline SO & $\begin{array}{l}\text { Maelic Anhydride Plant } \\
\text { Vent }\end{array}$ & $\begin{array}{l}\text { Formaldehyde, } \\
\text { Acetaldehyde, } \\
\text { Benzene }\end{array}$ & $\begin{array}{l}1214368 \\
(551409)\end{array}$ & $\begin{array}{l}-0.066 \\
(0.013)\end{array}$ \\
\hline $\mathrm{AP}$ & Methylamine Plant Vent & $\begin{array}{l}\text { Formaldehyde, } \\
\text { Acetaldehyde, } \\
\text { Benzene }\end{array}$ & $\begin{array}{l}1214368 \\
(551409)\end{array}$ & $\begin{array}{l}-0.066 \\
(0.013)\end{array}$ \\
\hline \multirow[t]{3}{*}{ SF } & Fugitive Emissions & Acrylonitrile & $25600000^{*}$ & $-3.225^{*}$ \\
\hline & Fugitive Emissions & Acrylonitrile & $25600000^{*}$ & $-3.225 *$ \\
\hline & Fugitive Emissions & Acrylonitrile & $25600000^{*}$ & $-3.225 *$ \\
\hline FG & Turbine & $\begin{array}{l}\text { Formaldehyde, } \\
\text { Acetaldehyde, } \\
\text { Benzene }\end{array}$ & 2248523* & $-6.307 *$ \\
\hline \multirow[t]{3}{*}{ SR } & Turbine & $\begin{array}{l}\text { Formaldehyde, } \\
\text { Acetaldehyde, } \\
\text { Benzene }\end{array}$ & 2248523* & $-6.307 *$ \\
\hline & Turbine & $\begin{array}{l}\text { Formaldehyde, } \\
\text { Acetaldehyde, } \\
\text { Benzene }\end{array}$ & 2248523* & $-6.307 *$ \\
\hline & TEG Reboiler & Benzene & 31863* & $-0.112 *$ \\
\hline
\end{tabular}

For cost parameters, numbers in parentheses indicate standard errors

*Standard errors could not be estimated due to low sample size 
Table 2 Emission Standards for Regulation at Various Spatial Resolutions (Threshold Risk = 1.0E-04; VSL=\$5.5 Million)

\begin{tabular}{|c|c|c|c|c|c|}
\hline \multirow[t]{2}{*}{ Facility } & \multirow[t]{2}{*}{ Pollutant } & \multirow{2}{*}{$\begin{array}{l}\text { Baseline } \\
\text { Emissions } \\
\text { (T/Y) }\end{array}$} & \multicolumn{3}{|c|}{ Optimal Emissions (TPY) } \\
\hline & & & Tract & $\begin{array}{l}\text { Block } \\
\text { Group }\end{array}$ & Block \\
\hline \multirow[t]{4}{*}{ IP } & Acetaldehyde & 5.5 & 149.6 & 149.6 & 196.4 \\
\hline & Formaldehyde & 8.5 & 0 & 0 & 0 \\
\hline & Acetaldehyde & 50.9 & 135.1 & 135.1 & 69.3 \\
\hline & Benzene & 5.08 & 0 & 0 & 0 \\
\hline \multirow[t]{3}{*}{$\mathrm{SO}$} & Formaldehyde & 0.0436 & 1.57 & 1.57 & 7.87 \\
\hline & Acetaldehyde & 0.00575 & 28.6 & 28.6 & 34.9 \\
\hline & Benzene & 0.00052 & 9.35 & 9.35 & 15.6 \\
\hline \multirow[t]{3}{*}{ SF } & Acrylonitrile & 2.819 & 0.11 & 0.11 & 0.03 \\
\hline & Acrylonitrile & 5.48 & 0.28 & 0.28 & 0.21 \\
\hline & Acrylonitrile & 1.159 & 0.17 & 0.17 & 0.07 \\
\hline \multirow[t]{3}{*}{ AP } & Formaldehyde & 0.869 & 0 & 0 & 0 \\
\hline & Acetaldehyde & 0.073 & 4.25 & 4.25 & 10.7 \\
\hline & Benzene & 0.03 & 0 & 0 & 0 \\
\hline \multirow[t]{7}{*}{ SR } & Formaldehyde & 30.52 & 1.02 & 1.02 & 1.07 \\
\hline & Acetaldehyde & 2.561 & 1.30 & 1.30 & 1.35 \\
\hline & Benzene & 1.0405 & 1.10 & 1.10 & 1.15 \\
\hline & Formaldehyde & 0.01027 & 1.06 & 1.06 & 1.11 \\
\hline & Acetaldehyde & 0.00135 & 1.34 & 1.34 & 1.39 \\
\hline & Benzene & 0.000123 & 1.14 & 1.14 & 1.19 \\
\hline & Benzene & 1.3 & 0 & 0 & 0 \\
\hline \multirow[t]{3}{*}{ FG } & Formaldehyde & 78.8 & 1.15 & 1.15 & 1.20 \\
\hline & Acetaldehyde & 6.615 & 1.43 & 1.43 & 1.48 \\
\hline & Benzene & 2.687 & 1.23 & 1.23 & 1.28 \\
\hline \multirow[t]{11}{*}{ GP } & Formaldehyde & 0.031 & 14.9 & 14.9 & 18.4 \\
\hline & Acetaldehyde & 0.000006 & 36.3 & 36.3 & 39.8 \\
\hline & Benzene & 0.00087 & 21.1 & 21.1 & 24.5 \\
\hline & Formaldehyde & 0.00098 & 24.2 & 24.2 & 27.0 \\
\hline & Acetaldehyde & 0.0000002 & 45.6 & 45.6 & 48.4 \\
\hline & Benzene & 0.000028 & 30.4 & 30.4 & 33.1 \\
\hline & Formaldehyde & 0.00228 & 37.8 & 37.8 & 40.2 \\
\hline & Acetaldehyde & 0.0000004 & 59.2 & 59.2 & 61.6 \\
\hline & Benzene & 0.0000621 & 44.0 & 44.0 & 46.4 \\
\hline & Nickel & 0.4095 & 0 & 0 & 0 \\
\hline & Arsenic & 0.438 & 0 & 0 & 0 \\
\hline
\end{tabular}


Table 3 Emission Standards for Regulation at Various Spatial Resolutions (Threshold Risk = 1.0E-05; VSL=\$5.5 Million)

\begin{tabular}{|c|c|c|c|c|c|}
\hline \multirow[t]{2}{*}{ Facility } & \multirow[t]{2}{*}{ Pollutant } & \multirow{2}{*}{$\begin{array}{l}\text { Baseline } \\
\text { Emissions } \\
\text { (TPY) }\end{array}$} & \multicolumn{3}{|c|}{ Optimal Emissions (TPY) } \\
\hline & & & $\begin{array}{c}\text { Census } \\
\text { Tract }\end{array}$ & $\begin{array}{l}\text { Block } \\
\text { Group }\end{array}$ & Block \\
\hline \multirow[t]{4}{*}{ IP } & Acetaldehyde & 5.5 & 112.0 & 113.9 & 96.9 \\
\hline & Formaldehyde & 8.5 & 0 & 0 & 0 \\
\hline & Acetaldehyde & 50.9 & 0 & 0 & 0 \\
\hline & Benzene & 5.08 & 0 & 0 & 0 \\
\hline \multirow[t]{3}{*}{ SO } & Formaldehyde & 0.0436 & 0 & 0 & 0 \\
\hline & Acetaldehyde & 0.00575 & 17.5 & 17.0 & 16.4 \\
\hline & Benzene & 0.00052 & 0 & 0 & 0 \\
\hline \multirow[t]{3}{*}{ SF } & Acrylonitrile & 2.819 & 0 & 0 & 0 \\
\hline & Acrylonitrile & 5.48 & 0.06 & 0.06 & 0.03 \\
\hline & Acrylonitrile & 1.159 & 0 & 0 & 0 \\
\hline \multirow[t]{3}{*}{ AP } & Formaldehyde & 0.869 & 0 & 0 & 0 \\
\hline & Acetaldehyde & 0.073 & 0 & 0 & 0.54 \\
\hline & Benzene & 0.03 & 0 & 0 & 0 \\
\hline \multirow[t]{7}{*}{ SR } & Formaldehyde & 30.52 & 0.90 & 0.90 & 0.86 \\
\hline & Acetaldehyde & 2.561 & 1.2 & 1.19 & 1.14 \\
\hline & Benzene & 1.0405 & 0.99 & 0.99 & 0.94 \\
\hline & Formaldehyde & 0.01027 & 0.94 & 0.94 & 0.94 \\
\hline & Acetaldehyde & 0.00135 & 1.22 & 1.22 & 1.22 \\
\hline & Benzene & 0.000123 & 1.02 & 1.02 & 1.02 \\
\hline & Benzene & 1.3 & 0 & 0 & 0 \\
\hline \multirow[t]{3}{*}{ FG } & Formaldehyde & 78.8 & 1.03 & 1.03 & 1.06 \\
\hline & Acetaldehyde & 6.615 & 1.31 & 1.31 & 1.35 \\
\hline & Benzene & 2.687 & 1.11 & 1.11 & 1.14 \\
\hline \multirow[t]{11}{*}{ GP } & Formaldehyde & 0.031 & 6.10 & 5.48 & 3.22 \\
\hline & Acetaldehyde & 0.000006 & 27.5 & 26.9 & 24.6 \\
\hline & Benzene & 0.00087 & 12.3 & 11.6 & 9.4 \\
\hline & Formaldehyde & 0.00098 & 15.4 & 15.2 & 13.3 \\
\hline & Acetaldehyde & 0.0000002 & 36.8 & 36.6 & 34.7 \\
\hline & Benzene & 0.000028 & 21.6 & 21.4 & 19.5 \\
\hline & Formaldehyde & 0.00228 & 29.0 & 29.1 & 27.4 \\
\hline & Acetaldehyde & 0.0000004 & 50.4 & 50.5 & 48.8 \\
\hline & Benzene & 0.0000621 & 35.2 & 35.2 & 33.5 \\
\hline & Nickel & 0.4095 & 0 & 0 & 0 \\
\hline & Arsenic & 0.438 & 0 & 0 & 0 \\
\hline
\end{tabular}


Table 4 Mean Individual Cancer Risk in EJ and non-EJ communities

\begin{tabular}{|l|l|l|l|l|}
\hline & \multicolumn{2}{|c|}{100 in a Million Threshold } & \multicolumn{2}{c|}{10 in a Million Threshold } \\
\hline $\begin{array}{l}\text { Resolution of } \\
\text { Regulation }\end{array}$ & $\begin{array}{l}\text { Mean Individual } \\
\text { Risk in } \\
\text { “communities of } \\
\text { concern” }\end{array}$ & $\begin{array}{l}\text { Mean } \\
\text { Individual Risk } \\
\text { for all other } \\
\text { communities }\end{array}$ & $\begin{array}{l}\text { Mean Individual } \\
\text { Risk in } \\
\text { “communities of } \\
\text { concern” }\end{array}$ & $\begin{array}{l}\text { Mean } \\
\text { Individual Risk } \\
\text { for all other } \\
\text { communities }\end{array}$ \\
\hline Census Tract & $12.4(\mathrm{n}=2446)$ & $9.6^{* *}(\mathrm{n}=4701)$ & $4.8(\mathrm{n}=2446)$ & $3.6^{* *}(\mathrm{n}=4701)$ \\
\hline Census Block & $14.1(\mathrm{n}=2446)$ & $10.7^{* *}(\mathrm{n}=4701)$ & $4.1(\mathrm{n}=2446)$ & $3.1^{* *}(\mathrm{n}=4701)$ \\
\hline
\end{tabular}

** Difference in mean individual risk between communities of concern and other communities is significant at 1\%; All cell values are " $n$ in a million" units 
Max. Ind. Risk: 187 in a Million; Population Risk: 0.00215 expected additional cancers
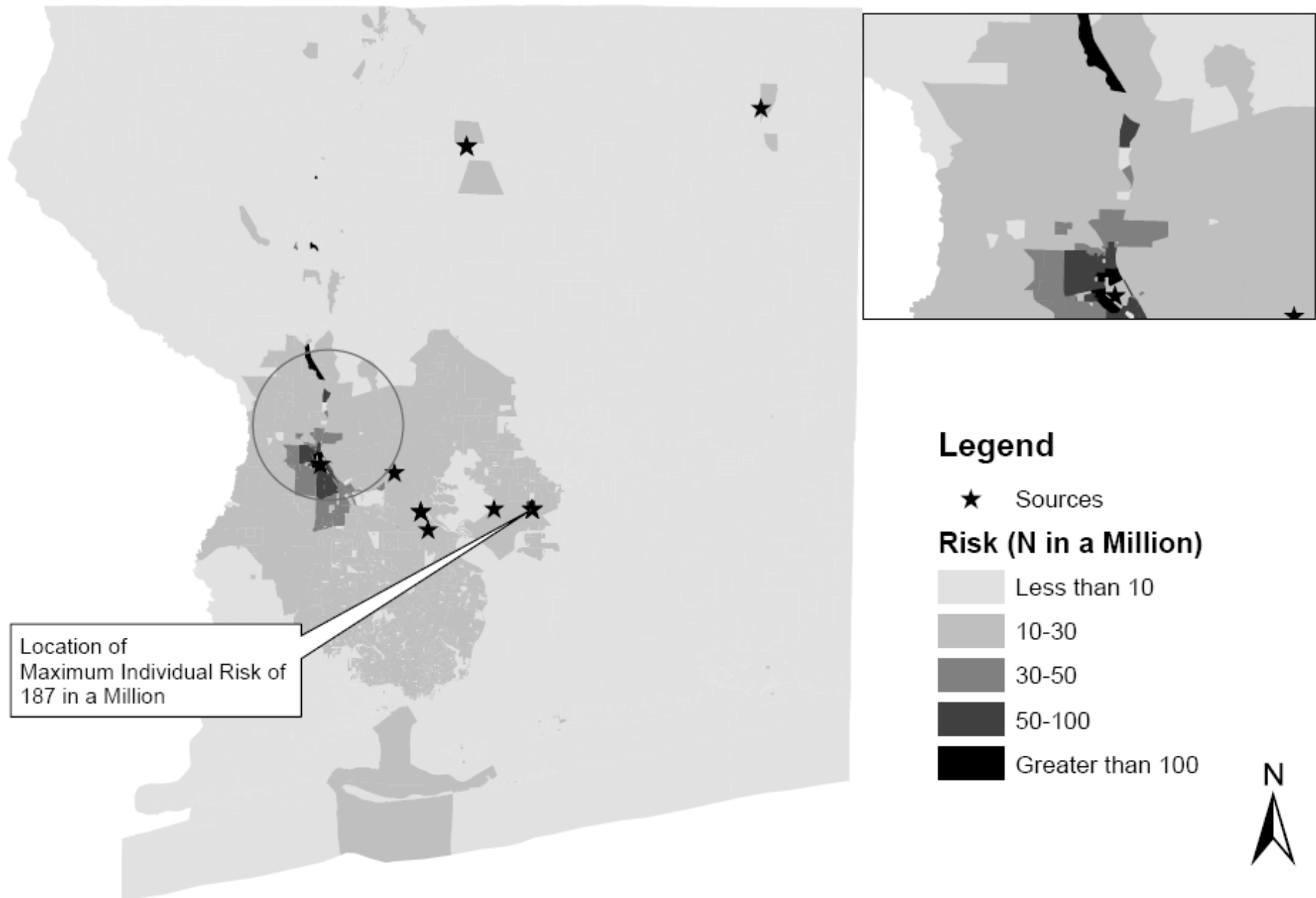

\section{Legend}

$\star$ Sources

Risk ( $\mathrm{N}$ in a Million)

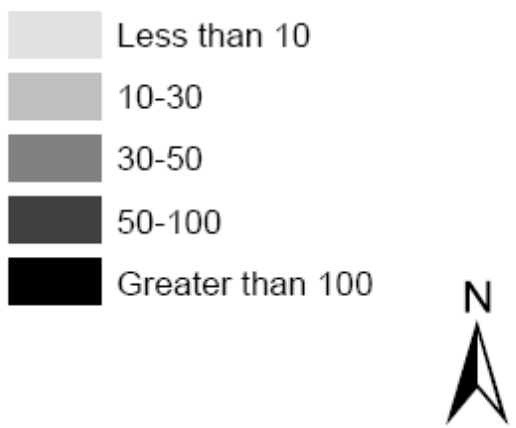

Figure 1 Spatial Distribution of Cancer Risks under Regulation at Census Tract Resolution (Cancer Risk Threshold of 100 in a Million) 
Max. Ind. Risk: 100 in a Million; Population Risk: 0.00244 expected additional cancers
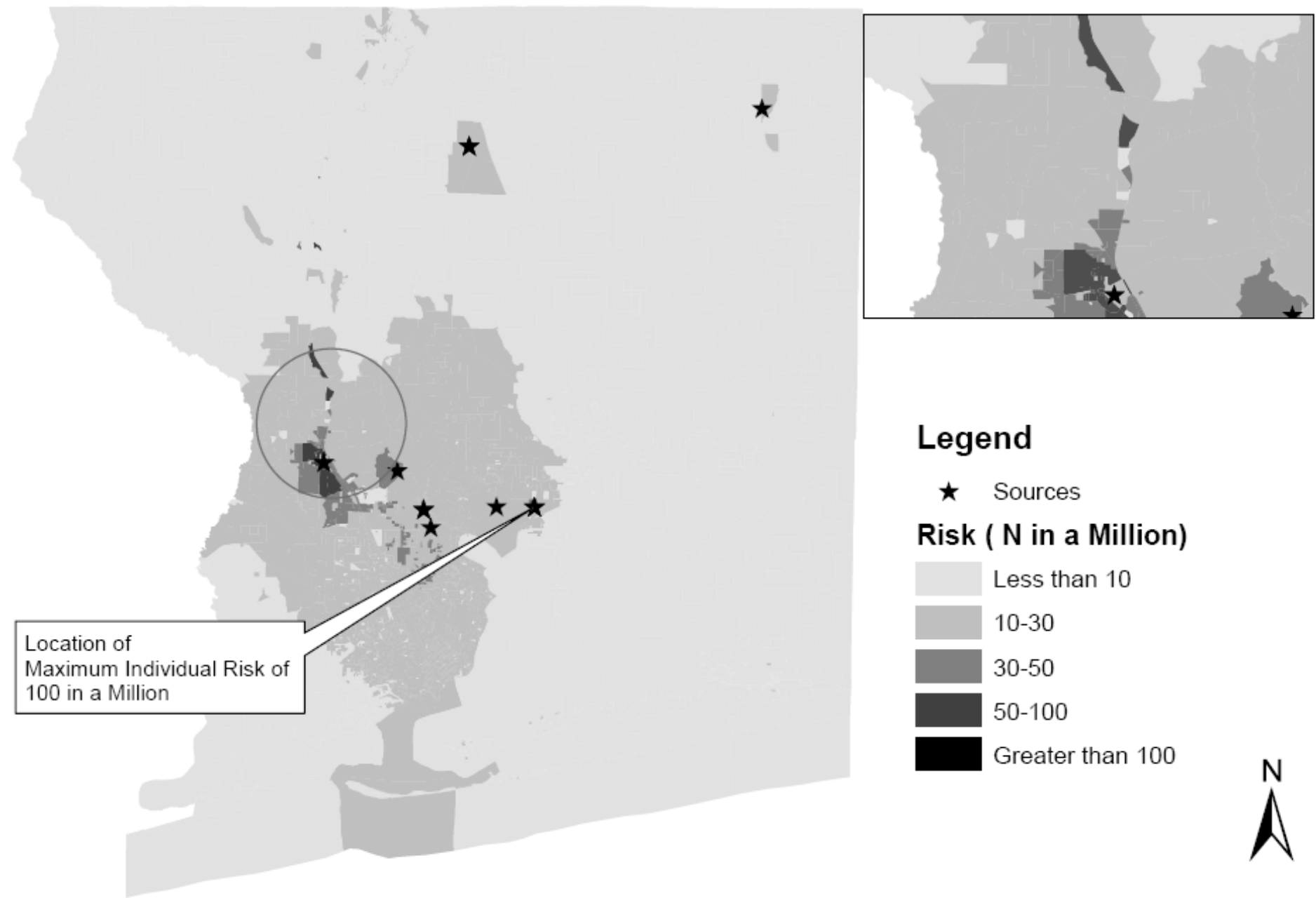

\section{Legend}

$\star$ Sources

\section{Risk ( $\mathrm{N}$ in a Million)}

Less than 10

$10-30$

$30-50$

$50-100$

Greater than 100

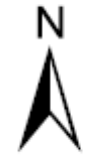

Figure 2 Spatial Distribution of Cancer Risks under Regulation at Census Block Resolution (Cancer Risk Threshold of 100 in a Million) 
Max. Ind. Risk: 17 in a Million; Population Risk: 0.0008 additional cancer cases

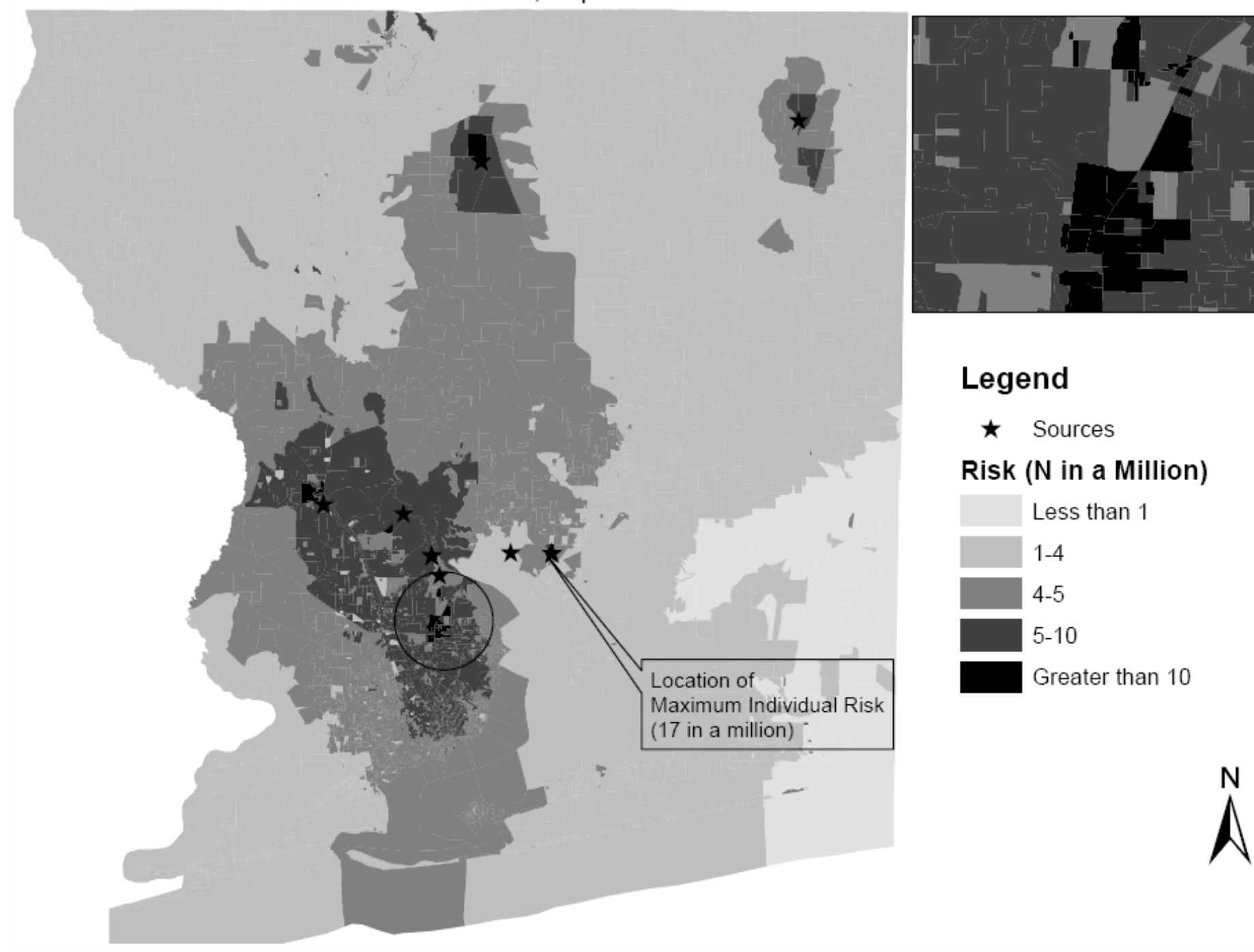

Figure 3 Spatial Distribution of Cancer Risks under Regulation at Census Tract Resolution (Cancer Risk Threshold of 10 in a Million) 
Max. Ind. Risk: 10 in a Million; Population Risk: 0.000689 additional cancer cases

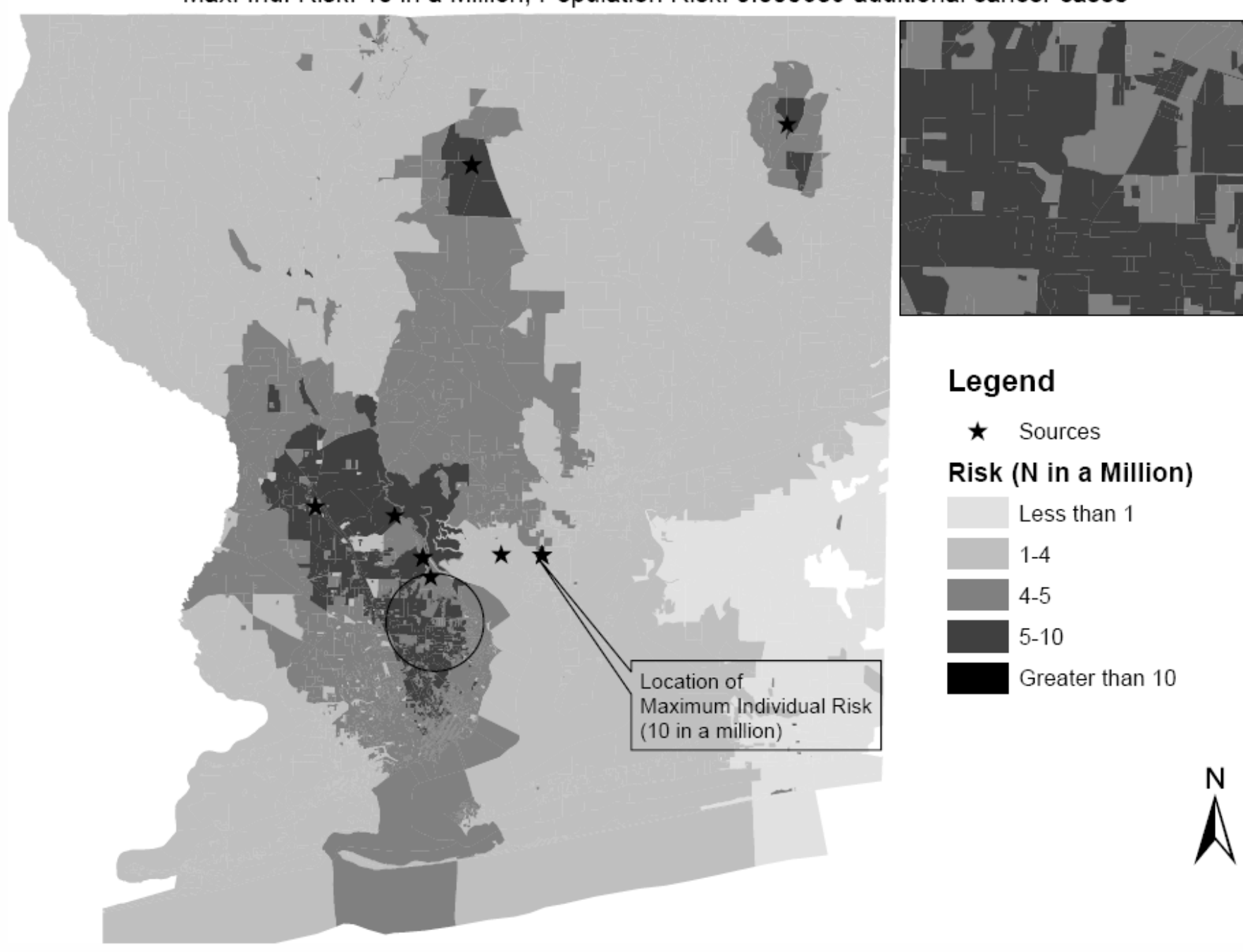

Figure 4 Spatial Distribution of Cancer Risks under Regulation at Census Block Resolution (Cancer Risk Threshold of 10 in a Million) 


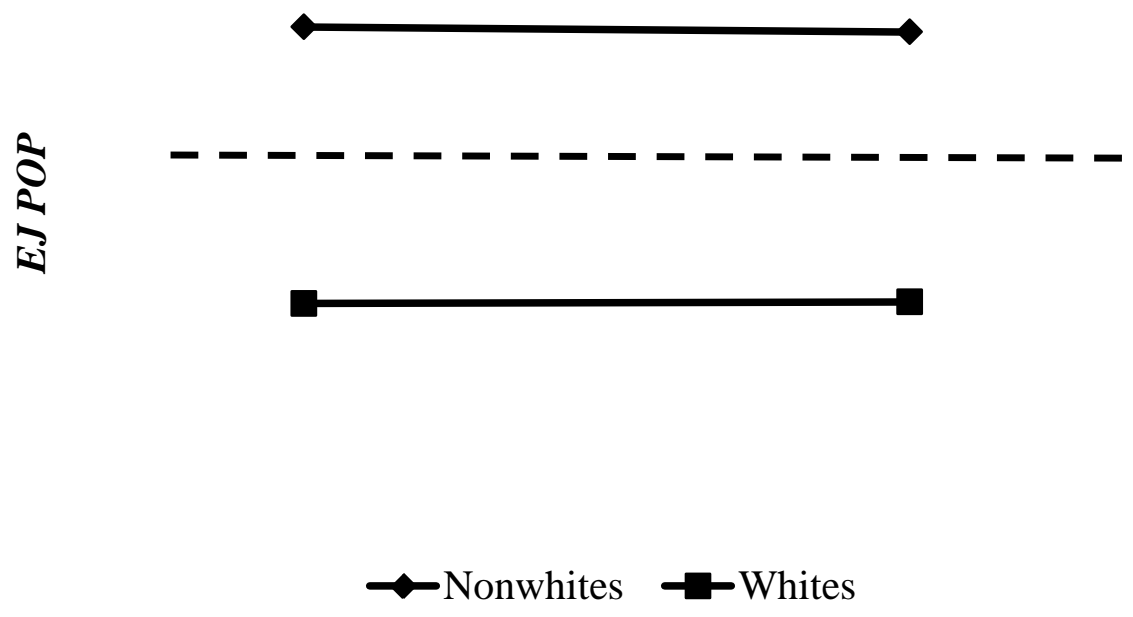

Figure 5 Share of Expected Additional Annual Cancer Cases Relative to Share of Population at Tract and Block Resolution of Regulation for Whites and Nonwhites (Risk Threshold: 100 in a Million) 


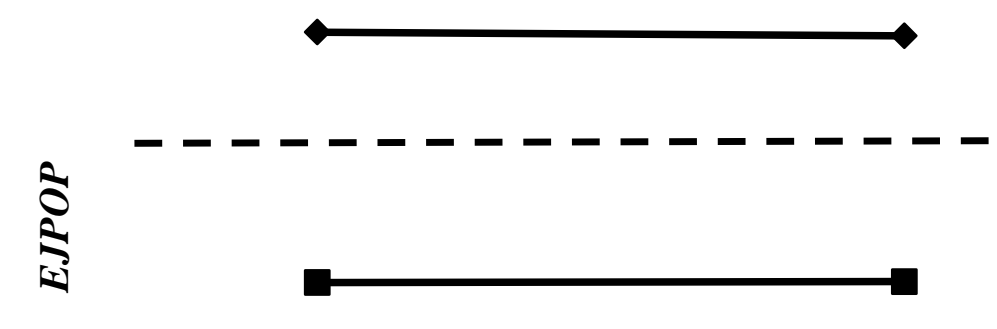

$\rightarrow$ Nonwhites $\rightarrow$ Whites

Figure 6 Share of Expected Additional Annual Cancer Cases Relative to Share of Population at Tract and Block Resolution of Regulation for Whites and Nonwhites (Risk Threshold: 10 in a Million) 